\title{
A propósito de Lugar
}

\author{
Juan Carlos Mondragón**
}

\section{Resumen}

Lugar es el último libro de relatos escrito por Juan José Saer. La comunicación, pretende explicar ese regreso puntual a la forma breve y halla explicaciones de tres tipos. La primera es la posibilidad de presentar en el mismo corpus una polifonía de voces y situaciones, un acceso a espacios y tiempos que, en su diversidad, confirman la modernidad. Luego, el cuento es observado en sus posibilidades técnicas, pero también en su vertiente de conocimiento específico, y que el autor denomina antropología especulativa. Por último, se acerca el proyecto Lugar a la noción de "fragmento" en la acepción crítica tal como es definida en los trabajos de T. W. Adorno; pérdida del centro, de la unidad, pero necesidad de la traza de un testimonio narrativo ante el caos del siglo XX.

\section{Palabras clave}

Antropología especulativa. Fragmento. Lugar. T. W. Adorno. Vertiente antropológica.

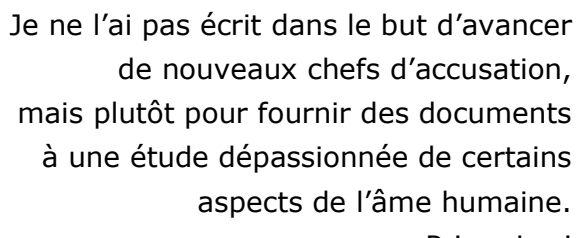

Primo Levi

¿Por qué Lugar? Hace unos meses, considerando la eventualidad del presente trabajo, me pregunté sobre qué aspecto de la literatura de Juan José Saer preferiría abordar. La duda parecía pertinente, era una secuela del encuentro sostenido con una escritura querida y admirada, traducía la perplejidad que provoca frecuentar una obra mayor.

La producción de Saer es considerable, compleja y seductora, exigente y abierta. Siendo un buen lector de su literatura preferí abandonarme a la espera de la empatía; para ello releí la totalidad de lo editado, aguardando la réplica de un personaje que me diera una pista, la resolución perfecta de una escena, la irrupción

\footnotetext{
* Universidad Lille III. El trabajo se publicó por primera vez en Actes 10. Actas del coloquio internacional La obra de Juan José Saer, La Grande Motte, mayo 2002, Centre d'études et de recherches sociocritiques, Montpellier.
} 
reconocible de un tema recurrente. Avanzaba en la lectura de manera aleatoria, hasta que en determinado momento me percaté de que cierta libertad, de la que yo creía disponer, era relativa y una evidencia se impuso: debía escribir sobre Lugar.

Una vez aceptada esa premisa y antes de abandonarme a lo que sería mi "corpus" quise hallar las razones que la motivaron. Las había de orden editorial, lo que tiene el libro de novedad, y las había también de orden privado, pero ambas categorías de explicaciones resultaban inadecuadas para devenir argumentos convincentes. En ello estaba cuando el texto, que siempre proporciona la prueba decisiva, me acercó el motivo concluyente. El fragmento al que me refiero lo pueden hallar en la página 83 de Lugar:

Existe siempre durante el acto de leer un momento, intenso y plácido a la vez, en el que la lectura se trasciende a sí misma, y en el que, por distintos caminos, el lector, descubriéndose en lo que lee, abandona el libro y se queda absorto en la parte ignorada de su propio ser que la lectura le ha revelado: desde cualquier punto, próximo o remoto, del tiempo o del espacio, lo escrito llega para avivar la llamita oculta de algo que, sin él saberlo tal vez, ardía ya en el lector.

Leyendo Lugar ese momento, que establece entre el texto y vivencias íntimas correspondencias imprevistas, ecos de otras lecturas, me llegó en varias oportunidades. Se trataba de una experiencia subjetiva, formaba parte del efecto objetivo de los veintiún relatos que contiene el libro y podía atribuirse a calidades de la prosa que yo daba por descontadas. Me pareció evidente que ese conjunto de narraciones y no sólo a mi de alguna manera alteraba "el arte detenido y rudimentario de la lectura", en especial de la obra de Saer, revelándome otros intercambios posibles entre la escritura y el mundo. Pero debemos ser prudentes en cuanto a la intensidad de la sorpresa. No se trataba de una modificación radical, sino de alteraciones precisas en la estrategia de escritura, indagaciones temáticas y propuestas de resolución formal que se agregaban a lo ya conocido. Se pueden manejar varias fórmulas para dar cuenta de la situación literaria distinta que nos propone el escritor. Creemos que la dualidad confirmación/riesgo puede ser adecuada; dialéctica sólo posible cuando sucede al interior de un territorio literario reconocible y confirmado, como es el caso. Lo nuevo se instaura a partir de terreno conocido. Sabemos, leyendo Lugar por primera vez, de una tranquilidad y esperamos que, en algún momento, el autor nos diga: tranquilos muchachos, que Tomatis está al caer, o el Matemático, o Barco.

Ello instaura la complicidad imprescindible para la nueva aventura, y entonces somos llevados a los campamentos que asedian ilusión de Troya, a Londres sacudida por un crimen horrendo, a una caminata por la mismísima luna. Esa movilidad, fascinante e intensa, esa escritura en expansión, constituye el factor inesperado a que hacíamos referencia. El último libro de Saer es un cuaderno de variaciones narrativas que movilizan el concepto de "lugar", idea central de su estética, fórmula recurrente que aparece en su narrativa, la prosa ensayística y la poesía; transfigura de manera febril la noción de relato instalándola en la memoria colectiva y en los procedimientos íntimos de supervivencia, en su función subjetiva y social. Bajo una apariencia formal que recuerda cuentos, narraciones, relatos y textos, la escritura saeriana se inscribe en una poética del fragmento, estructuras sin canon y halladas en la "intemperie" del siglo XX. 
Esas serían las trascendencias de la lectura a que nos referíamos. Si se prefiere: lugar, especie y fragmento. Lo que nos parece relevante es que los tres aspectos señalados funcionan en conjunto, tienen una dependencia mutua: participan de una necesaria complementariedad. Los tres síntomas, o evidencias, o intuiciones responden a la hipótesis de lectura que podemos avanzar. Lugar es una puesta en funcionamiento, hasta sus extremas consecuencias, mediante un dispositivo astuto y complejo, de um juicio que el escritor postulara en un ensayo: "podemos definir de un modo global la ficción como una antropología especulativa". Ello ya sucedía en títulos anteriores del autor, pero el aporte de Lugar es la valoración de la definición citada, mediante la fractura de la unidad novelesca y la proliferación de entidades narrativas, y proponiendo un sistema "temático-narrativo-formal" específico. La resultante se alinea con el conjunto de ideas que podemos denominar "las opiniones de Saer relativas a la literatura" y que se corresponden con esta posible "vertiente antropológica" que nos parece preside el proyecto considerado. Pueden citarse, a manera de ejemplo: a) que la literatura puede considerarse una crítica del mundo, en su organización social y en su condición de "objeto de experiencia y conocimiento"; b) que dentro de toda narración hay una teoría narrativa; c) que todo escritor debe fundar su propia estética. Hay más, pero lo interesante es observar esa tensión entre una praxis de la escritura y un pensamiento que la sustenta, tanto en la fricción con otros discursos, como en la problemática dEl arte de narrar.

La prioridad "vertiente antropológica" no opaca lo narrativo, por el contrario, lo enriquece. Nos permite ubicar el proyecto Lugar en una filiación ideológica, al interior de un territorio del pensamiento crítico, en una biblioteca también filosófica.

1. Lo que llamamos "vertiente antropológica", tiene en la obra de Saer un espléndido antecedente en la novela El entenado, de 1983; no sólo porque se construye sobre episodios que tensaron al máximo la antropología especulativa señalada, sino también por la sublimación ontológica, religiosa e histórica de la función y El arte de narrar y luego, por añadidura, de la escritura, que puede preservar memorias de poblaciones exterminadas. Así, pues, la cuestión del "otro", la visión del mundo que se brinda un grupo, tribu o imperio, así como el imperativo de narrarlo, es en Saer preocupación de larga data.

Puede decirse otro tanto de la exploración de lo "humano", desde las pulsiones, biológicas, incontrolables, que determinan las conductas del ser antes del contrato histórico y social, hasta la evolución que conduce al excedente definidor del arte, hasta la destrucción ilimitada. En cuanto a los indios de El entenado, nada mejor que esas poblaciones desamparadas del otro plan venido de ultramar, para observar el laboratorio de la tentación del hombre occidental para eliminar al diferente, nada mejor que la colonia para aceitar el mecanismo que llevó a la guerra permanente. Aquellos seres que vivían según los ritmos naturales de la orgía ritual, el respetuoso consumo del cuerpo enemigo y la sorpresa cósmica de un eclipse, ya sabían sobre la necesidad del relato para dejar constancia de su pasaje por la realidad. También demostraron, al precio de su desaparición de la faz de la tierra, lo que formulara Adorno sobre que, ninguna historia universal, lleva del salvaje al esplendor de la humanidad civilizada, pero hay un itinerario, probable, que conduce de la honda a la bomba atómica. 
A ese antecedente Lugar le incorpora la multiplicación de espacios y circunstancias, de ámbitos desconcertantes y mentalidades en las antípodas aparentes de los indios Colastiné. Expansión que no pretende ser demostración de pericia sino la tentativa, lograda, de otro eje de la escritura de Saer, que es el tránsito entre lo particular y lo universal. El libro puede ser leído como una expedición a las fronteras de la imaginación y las incertidumbres del género; incita a la utilización, llámese de aparatos críticos, de lecturas, que también deben conectar la anécdota minimalista y otros discursos más expandidos.

Entre dos relatos, que rondan la incidencia del sueño en la realidad y viceversa, sin embargo el Tiempo-Historia que transita el libro está acotado. Va desde fines del siglo XIX hasta el momento de la escritura de algunos relatos del libro, que pueden datarse, con bastante aproximación, hacia 1998. Saer, con mirada de narrador, busca en los intersticios de la subjetividad e indaga en la tenaz repetición de algunos fenómenos. El itinerario lo lleva desde la búsqueda del hombre "no cultural", hasta la conciencia de la creación artística, si ello es todavía posible, si se restaura el equilibrio perdido entre lo visible y lo invisible, después de Tchernobyl. Los espacios, por el contrario, se disparan. Los protagonistas son elegidos con sumo cuidado: un anciano judío ateo y materialista, un astronauta desencantado y filosófico, los vecinos de una central nuclear, los alienados sobre la cuestión del doble en la Berlín escindida, y los negros basureros de París que la sociedad obliga a ser africanos en la plaza Vandôme. Son nuestro contemporáneos y habitan nuestro mismo lugar. Cuando todo tiende a ser equiparable Saer instaura la pluralidad, cuando el mercado impone la novela como único género totalitario, recuerda que las hipóstasis del relato pueden ser infinitas.

En el modelo Saer "lugar" es más que la denominación del espacio. Al interior de su sistema estético y de la teoría narrativa que rige su escritura, es lo que más se acerca al misterio de la creación literaria. Se trata de un concepto a la vez evidente e inasible. Lo argumenta en los ensayos, lo puso en práctica en los relatos, esa polisemia es signo de procesos interiores y está asociado a pulsiones vinculadas al deseo de escribir. En su ensayo "El concepto de ficción" se lo define de la siguiente manera:

\begin{abstract}
Por otra parte, el escritor escribe siempre desde un lugar, y al escribir, escribe al mismo tiempo ese lugar, porque no se trata de un simple lugar que el escritor ocupa con su cuerpo, un fragmento del espacio exterior desde cuyo centro el escritor está contemplándolo, sino de un lugar que está más bien dentro del sujeto, que se ha vuelto paradigma del mundo y que impregna, voluntaria o involuntariamente, con su saber peculiar, lo escrito.
\end{abstract}

Ese posible territorio interior, ese sitio, que acaso prescinde de las condiciones de producción, produce a través de los relatos sus propias figuras.

Titular un libro Lugar es colocar el concepto en el centro del proyecto; así, para un libro que evoca los infiernos del siglo pasado es determinante el acápite del canto I del Paraíso, donde se evoca otro entorno: "Mucho es permitido allí que aquí no se permite a nuestras facultades, merced a que aquel lugar se creó para la especie humana", dice la versión española de la BAC. Incluso los elementos paratextuales reactivan la potencia del concepto referido. Lugar es misterio y revelación, los relatos, 
además de materializar en la escritura diversas pulsiones que se originan en el lugar (concepto), buscan transformarse en símbolos de lo humano ahora en distintos lugares (espacio). La supremacía en dos instancias de la textualidad parece indicar que el "lugar" se moviliza modificando, las historias, las formas, el estrato simbólico que condiciona la interpretación. Lo que unifica quizá sea lo antropológico, la instalación en la experiencia humana probando los matices plurales, buscando las partes dañadas y no dañadas por las fuerzas negativas operando en nuestra civilización, indagando zonas oscuras y luminosas del ser, aceptando la dinámica de la historia pero destacando la subjetividad.

Si un antecedente de vida "no cultural" aparece en tanto probabilidad incierta e indemostrable, Lugar asume las peripecias del hombre cultural en el grado de evolución donde parecemos situarnos. En cada narración, si se acepta la recurrencia señalada a la vertiente antropológica, se produce el encuentro de lo señalado en el párrafo anterior y los procedimientos materiales de la escritura, que evitan la similitud, para que cada pieza sea diferente por completo de las restantes. Estamos en una situación lógica y paradojal: lo particular y lo universal, las partes y la sospecha del todo subterráneo. Se impone la necesidad de transitar por categorías generales y lo conveniente de recordar que aquí la metafísica no es una rama de la literatura fantástica.

Pongamos un ejemplo concreto, donde la polisemia del concepto lugar nos permite observar el entorno y la filosofía, la experiencia del mundo y cierto egoísmo de la materia, la importancia del sueño y el lenguaje. "Nieve de primavera" es un relato que apreciamos particularmente. Allí, una pareja de italianos ya mayores, pasean por Viena un sábado de mañana, cuando el centro es más movido con sus comercios y mercados. Una tormenta los lleva a refugiarse en una taberna griega. La mujer, en el relato, describe dos escenas que se suceden en las mesas contiguas. Las muestras de afecto de un niño a su madre, mujer particularmente fea, y el discurso encendido de un anciano, que ridiculiza la cultura y reivindica los sentidos inmediatos apelando a una línea argumental basta. Más simple imposible, y sin embargo hay en la narración la historia de la estética occidental, y la cuestión entre el falso y el verdadero epicureísmo, hasta puede que asistamos a una manifestación griega del complejo de Edipo. El cuerpo y el alma, lo bello y lo concreto, lo pasajero y lo eterno. La experiencia individual no desplaza lo filosófico, lo intensifica. Como dice Saer en otro momento, no estamos aquí para delirar.

El discurso del anciano, que habla alemán en una taberna griega en la capital austríaca, es ya todo un programa. Tiene 83 años, su salud es envidiable y su vida sexual activa es reivindicada con orgullo entendible. Pertenece, con una pequeña diferencia de años, a la misma generación de Goldstein, el personaje de "Con el desayuno" y ejemplifican dos destinos distintos de la juventud europea. No es improbable que se hubieran cruzado desde dos lugares distintos de la Historia. Saboreando su comida y su vino, haciendo la apología grosera de ese instante, se mofa de Schubert y del arte, también de las teorías de Freud; y ello sucede en Viena, la ciudad denigrada por Thomas Bernhard, de Wittgenstein que trabajó sobre los límites, imposibilidades y aporías del lenguaje, y las virtudes del silencio. 
La idea de lugar, que es a la vez concreta e indeterminada, asociada a la experiencia poética, está sujeta a desplazamientos. Nos limitamos a constatar una actividad de inusitada importancia al respecto.

2. La "vertiente antropológica" nos conduce a la zona de turbulencia donde coexisten verdad y ficción. Saer lo declaró de forma inequívoca en varios de sus ensayos. La ficción no es ejemplo narrativo de ideas o teorías, sino que es concebida como un conocimiento específico del mundo y de la especie. De ello hace un principio riguroso de su poética, con la finalidad de evitar la confusión de géneros.

Se advierte así una temprana preocupación por esa zona donde relato y pensamiento tienden a acercarse. Ello, a la vez que postula la incontaminación del relato, evidencia un interés de larga data por la circulación de las ideas en la narración, y deja constancia de ello en el ensayo "El concepto de ficción":

Pero que nadie se confunda: no se escriben ficciones para eludir, por inmadurez o irresponsabilidad, los rigores que exige el tratamiento de la "verdad", sino justamente para poner en evidencia el carácter complejo de la situación, carácter complejo del que el tratamiento limitado a lo verificable implica una reducción abusiva y un empobrecimiento. Al dar el salto hacia lo inverificable, la ficción multiplica al infinito las posibilidades de tratamiento.

Saer no está en un proceso de reconversión a la filosofía. Sí parece decidido a una extensión del espacio literario, a indagaciones en terrenos inusuales motivado por la relación entre lo particular y lo universal.

La "vertiente antropológica" acelerada no disminuye en nada el elogio del relato que atraviesa la obra de Saer. Coro o murmullo, polifonía o secreto de la subjetividad, la complejidad de anécdotas se acompaña con la apoteosis de la ficción, inseparable de la aventura humana. Ese elogio del narrar se concreta de diversas maneras, comienza por un ajuste del tiempo histórico que se adecua a la "vertiente antropológica", y por aislar un episodio (los campos de concentración y la palabra de los supervivientes) que afectó el conjunto de convicciones que operan en la obra de Saer: la condición humana, la escritura, la posibilidad del arte después de lo inenarrable, el imperativo casi biológico de narrar, la formulación eficaz del pensamiento, la memoria de lo desaparecido, el intelectual en el exilio, la función de los relatos en la vida social. Una conocida fórmula parece ajustarse a lo dicho: la función del arte consiste en introducir el caos en el orden.

Incluso en los tiempos históricos, como si asistiéramos a una Historia regida por otras fechas. Al interior de ese sistema, del que Lugar da cuenta, la caída quizá comenzó en 1888. En Londres, con los afanes jamás dilucidados del llamado Jack que hizo del asesinato en serie un gesto que concilió poesía popular y horror; y en Turín cuando Nietzsche vive sus últimos días de vida conciente, antes que lo cubriera el manto de la locura. Quizá el siglo pasado, en otro sistema de pautar el pasaje del tiempo, que se desentiende de los hechos más espectaculares y se mide por los desastres de significación humana, no acabó con la caída del muro. La esperanza en la ciencia absoluta terminó el 25 de abril de 1986 cuando explotó el gran reactor; un cierto optimismo se desmintió en Turín, otra vez, el 11 de abril de 1987 cuando Primo 
Levi se tiró al vacío en su casa. Primo Levi cuenta al comienzo de "Si, es un hombre" que salir de los campos se soportaba por el deseo de contar a los otros, que se volvía una pulsión tan imperiosa como las otras necesidades y que escribir era una liberación interior.

En Saer es un tema conocido. El elogio de la narración y la función que cumple en la vida social, el valor de revelación, que provocan los relatos en la vida privada. En cuanto a ello, El entenado tiene pasajes estupendos:

\begin{abstract}
De mi esperaban que duplicara, como el agua, la imagen que daban de sí mismos, que repitiera sus gestos y palabras, que los representara en su ausencia y que fuera capaz, cuando me devolvieran a mis semejantes, de hacer como el espía o el adelantado que, por haber sido testigo de algo que el resto de la tierra todavía no había visto, pudiera volver sobre sus pasos para contárselo en detalle a todos. [...] querían que de su pasaje por ese espejismo material quedara un testigo y un sobreviviente que fuera, ante el mundo, su narrador.
\end{abstract}

Continuando en esta línea, pero invirtiendo los términos de narrador y referente, en Lugar quizá el ejemplo más interesante sea el relato "Traeré". Allí, con motivo del encuentro a la vez casual e intencionado de dos barrenderos africanos se produce el vértigo de las historias: la historia del trabajo en ese lugar, que es la plaza Vandôme; la historia de la amistad entre el musulmán que cree en la verdad del Libro, y otro que improvisa a partir de noticias periodísticas. La historia de los "griots", narradores de la tradición oral, de la que uno de los barrenderos sería dudoso heredero. La historia, con matices sórdidos y mágicos, próximos y lejanos, del asesino que da título, con su nombre, al relato. Los marginados son los que reconstruyen un mundo, una tradición, un personaje, y forman la escena básica para que se opere la máquina de los relatos.

Estamos ante uno de los temas transversales de la narrativa de Saer, frente a uno de los pilares de su sistema. Podemos percibir dos rasgos específicos en la propuesta de Lugar que merecerán más extensas reflexiones, y por ello aquí sólo serán mencionados al pasar. El primero, del que "Traeré" es un excelente ejemplo, es el vértigo que se propone en la actitud de narrar. Hay una aceleración de la pulsión narrativa: por teléfono y por carta, en meditaciones mañaneras durante el desayuno y en la oscuridad del dormitorio, mientras se espera que pare la lluvia en un bar de estación, durante una nevada primaveral. $Y$ los que no cuentan, prometen escribir tratados, escribir, o enviar manuscritos, o quedan a la espera de respuestas. En el siglo de la reproducción mecánica del arte, y que vio la confiscación industrial del relato Lugar devuelve el narrar al dominio de la subjetividad, restituye la función relativa a la autenticidad y ritual dentro del sistema social. El hombre es la especie que narra.

Creemos observar otro movimiento que se orienta al interior de los relatos. De la misma manera que el tío de Tomatis ensaya la introspección a la búsqueda del hombre "no cultural", episodio curioso que lleva al narrador a repetir, diecinueve veces, la fórmula "le escribe", cada relato de Lugar -o casi todos- parecen ir a la búsqueda de un "proto" cuento. Se impone el deseo de alcanzar una matriz, la maqueta primera. Quizá esta "variante relato inicial" sea no consecuencia de la "variante antropológica" sino causa. Es posible, pero, en todo caso, aparecen como 
indisociables. Como la unidad que forman Finá Kamara, el barrendero que narra y el musulmán hipnotizado que escucha, en invierno, en la plaza Vandôme, en París, el trágico destino de Traoré.

3. Ello nos conduce al tercer aspecto que deseamos evocar. Nos referimos a la opción que Saer hace en Lugar por la forma breve. Estamos en el terreno de las definiciones y por esta vez diríamos que, más que ante cuentos, preferimos referirnos a narraciones proteicas que asumen la forma de fragmentos. Vemos en ello una continuidad necesaria, una conclusión que parece imponerse. Decimos esto porque la línea que dimos en llamar "vertiente antropológica", en cuanto se declina en diferentes historias, requiere una alternancia formal que impida la dispersión y que evoque un origen común.

En cuanto a la forma breve, en la obra de Saer hay antecedentes. En Lugar el cambio es significativo y lo formal se corresponde al despliegue temático. El fragmento resulta de una coherencia y en tanto forma, trasciende el cuento habitual para incorporarse a un movimiento más amplio, que afecta a buena parte de la mejor ficción del siglo pasado y a la escritura filosófica. El plan original era estimulante y peligroso, y al final la excelencia resulta de la adecuación entre el qué representar y el cómo hacerlo. La brevedad demuestra la capacidad de las pulsiones de los relatos del libro para hallar sus propias formas. Podría tentarse una confrontación con la forma novela; sucede que Lugar no es una tregua de la novela, ni un proyecto abiertamente en contra de la novela, género del que Saer sostiene que está en pérdida de capacidades críticas, pudiera serlo pero no lo es. La opción del fragmento parece resultar de la indagación polifónica en la antropología especulativa y ello concretado desde un paisaje mental y formal propio del siglo XX.

Lo pequeño, la escritura fragmentada es una figura de resistencia. El fragmento nos induce a mirar la catástrofe, asumir los monstruos que nos rodean sin confundirnos con ellos. Lo propio del fragmento es volcarse hacia gestos excluidos y olvidados, como si El arte de narrar incursionara en sus arrabales. Determinante en este proceso es la experiencia de los campos de concentración. Es coherente que, en el plan del libro, el relato "Con el desayuno" tenga una ubicación central, de donde irradia no sólo la confirmación de la "vertiente antropológica", el parentesco de los temas tratados, sino incluso la adecuación formal. La historia que se cuenta es sencilla: un sobreviviente de los campos, internado dos años por el triple delito de ser "judío, comunista y miembro de la Resistencia", retirado de su librería, lleva, a los setenta y seis años, una vida solitaria. Todas las mañanas toma el desayuno en un café de Buenos Aires y medita sobre la historia pasada. Ese es el momento, por la historia contada, por la ampliación de la crisis, donde la "vertiente antropológica" conoce su mayor cuestionamiento y lleva a un final desconcertante: "El crimen, la tortura, las masacres definían mejor a la especie humana que el arte, la ciencia, las instituciones", dice el personaje.

Lo que "Con el desayuno" cuenta es el cruce de caminos de la historia del hombre ( $\mathrm{y}$ todos sabemos las implicaciones históricas, metafísicas y cotidianas que ello supuso), con la secuela conocida en el arte, la ciencia y las instituciones. Enclave decisivo pues, el episodio que alteró, también, la vida intelectual, que incorpora y 
pensamos en Adorno, la categoría del pensamiento en exilio y proyecta la poética del fragmento como salvación para evitar caer en el desencanto absoluto. Lo pequeño se volvió una opción formal, des esperada, con fundamento ético, necesaria ante un pensamiento filosófico que se había vuelto nada más que método. Una línea de reflexión que se torna hacia lo subjetivo, el detalle, lo dejado de lado. Es el planteo que se halla en la Mínima Moralia y que puede ayudar a descifrar algunos sentidos del último libro de Saer.

Por ello la importancia ritual de las mañanas de Goldstein el sobreviviente, que medita en "Con el desayuno". Las secuelas del desayuno se suceden en dos tiempos, y la lectura del diario, los gestos pequeños que preparan la meditación: actividad de la memoria y de la inteligencia, afluencia de imágenes y pensamientos. El cotejo no puede ser más devastador. La asociación del sobreviviente, en el año 1998, confrontado a la serie de masacres del siglo, desde los armenios a los tutsis, las muertes originadas por cierto principio de identidad resuelto en el genocidio, parece llamar a lo terrible. Las masacres evocadas por Goldstein, sin privilegiar ninguna, muestran una sórdida continuidad que sólo Dante pudo intuir en el terceto que se cita: "Detrás venía tan gran muchedumbre de personas, que nunca hubiera creído que a tantos hubiera destruido la muerte".

La forma fragmentaria, incluso en el interior de cada relato, es la forma apropiada para expresar el nuevo proyecto. Lugar es algo parecido a eso: la indagación en lo cotidiano para marcar la distancia de un mundo en permanente lógica de guerra, el buceo en la pareja para descubrir sus círculos infernales, la escucha de lo que nunca será escrito porque está destinado a la tradición oral, y hasta la especulación con enigmas policiales, que pudieron haber sucedido en el pasado. La operativa del fragmento se encadena. Apenas agregamos otro ejemplo, citamos un relato al azar, la historia así seleccionada propone sus circuitos de ecos y anécdotas, y la deriva puede resultar ingobernable. Los trayectos del libro, acorde a su carácter fragmentario, son oblicuos, tangenciales y sinuosos. El relato fragmento (una definición sujeta a los condicionamientos avanzados, y a la espera de ciertos ajustes terminológicos imprescindibles), revela una coexistencia del mundo evocado y la operación de leer. Quizá por ello mismo se advierte cierta sensación de fragilidad que desprenden los relatos, hechos de la materia oral y la repetida experiencia del dislate, del irracionalismo por exceso y la erosión de las pesadillas, del disgusto de la utopía desencantada y la transparencia de ciertas experiencias -sueños ahora, lecturas, recuerdos de la infancia- que nos interpelan sin cesar.

En el segundo círculo del infierno, para inducir la imagen de las almas atormentadas, Dante las compara a grullas y estorninos lanzados en un torbellino eterno. Leyendo "Gens Negra", relato que integra el último libro de Saer, las aves evocadas son cuervos y mirlos, que se atreven al infierno urbano del hombre moderno, y el narrador, empleado administrativo de los ferrocarriles, dice refiriéndose a los cuervos: "o quizás adivinan, por la posición del sol en el cielo que a nosotros, seres horizontales, nos es indiferente, que algo esencial sucede en el universo y ellos, a su modo, con su vuelo solemne, lo celebran". 
Esas correcciones topográficas del lugar de la escritura, la voluntad de poner al hombre en el centro del relato y la recuperación del fragmento a conciencia que dio cuenta de la vida dañada, le asignan a Lugar un sitio privilegiado en el sistema Saer. El libro, que recién comienza el itinerario de sus significados, tranquilizaría a la Beatriz crítica de arte que, en el mismo canto I del Paraíso, un poco más adelante del acápite de Lugar, sostiene que, como la materia es sorda para responder, muchas veces la forma no concuerda con la intención en el arte; a ella se le podría responder: no comparto, y agregar que algunas veces esa recóndita armonía se produce.

\title{
Bibliografía
}

ADORNO, Theodor W. Mínima moralia. Madrid: Taurus, 1975.

SAER, Juan José. Lugar. Buenos Aires: Seix Barral, 2000.

El entenado. Buenos Aires, México: Folios, 1983.

. El concepto de ficción. Buenos Aires: Norma, 1997.

\begin{abstract}
Lugar is the last book of tales written by Juan José Saer. The Communications intends to explain that punctual regress to the brief form and finds explanations related to three types. The first is the possibility to present at the same corpus a polyphony of voices and situations, an access to spaces and times that in its Diversity confirms the modernity. Then, the tale is observed in its technical possibilities, but also in its specific knowledge aspect, which the author denotes as speculative anthropology. Finally, the project Lugar approaches to the notion of "fragment" in the critical meaning just as it is defined in the works of T. W. Adorno. Loss of the center and unity, but the need of the devise of a narrative witness in view of the chaos installed in the 20th century.
\end{abstract}

\section{Keywords}

Speculative anthropology. Fragment. Lugar. T. W. Adorno. Anthropological aspect. 